\title{
Cyclodimerization of Alkynes with Phosphine-Free Ruthenium Carbene Complexes: Carbene Consumption by a Shunted Alkyne Oligomerization
}

\author{
Steven T. Diver*, Amol A. Kulkarni, Daniel A. Clark and Brian P. Peppers \\ Department of Chemistry, University at Buffalo, the State University of New York, \\ Amherst, NY, 14260-3000
}

\section{SUPPORTING INFORMATION}

\section{General Experimental}

All reactions were conducted in an oven-dried or flame-dried glassware under a positive pressure of Argon (Ar), unless otherwise noted. Dichloromethane $\left(\mathrm{CH}_{2} \mathrm{Cl}_{2}\right)$ (alumina), toluene (alumina + Q5) and benzene (alumina + Q5) were drawn from a solvent purifier immediately prior to use. Ethereal solvents were either distilled from sodium/benzophenone under Ar or obtained from solvent purifier (alumina). Ruthenium [1,3-bis-(2,4,6-trimethylphenyl)-2-

imidazolidenylidene]dichloro(phenylmethylene)(tricyclohexylphosphine) (Grubbs second generation catalyst, 2), the first generation Hoveyda complex 4 and the second generation Hoveyda complex 1A were obtained from Materia, Inc. and used without any further purification, unless otherwise noted. The pyridine solvate $\mathbf{3}$ was synthesized immediately before use according to the literature. ${ }^{1} 1,5$-Cyclooctadiene was purified by distillation from sodium immediately prior to use. All alkynes were purified either by flash column chromatography using silica gel or by distillation immediately prior to use. All other reagents were purchased from Aldrich and used without further purification unless otherwise noted. Thin layer chromatography was conducted on glass backed EM science F254 silica plates. Visualization was accomplished with ultraviolet light, iodine or $10 \%$ phosphomolybdic acid solution in ethanol. ${ }^{1} \mathrm{H}$ and ${ }^{13} \mathrm{C}$ NMR spectra were recorded in $\mathrm{CDCl}_{3}, \mathrm{C}_{6} \mathrm{D}_{6}$ or $\mathrm{CD}_{2} \mathrm{Cl}_{2}$ at the indicated frequency either on a Varian Gemini-300, Inova400 or Inova-500 spectrometers. ${ }^{1} \mathrm{H}$ NMR chemical shifts were reported in parts per million (ppm) downfield from TMS and ${ }^{13} \mathrm{C}$ NMR referenced at $77.0 \mathrm{ppm}$ for $\mathrm{CDCl}_{3}, 128$ ppm for $\mathrm{C}_{6} \mathrm{D}_{6}$. GC mass spectra were obtained on a benchtop HP-5972 gc/mass spectrometer. High dilution EI mass spectra and high-resolution FAB mass spectra were obtained on a VG 70-SE mass spectrometer. IR spectra were recorded on a Nicolet Impact Series 420 IR or a Novolet Magna series 550 IR. The syringe pump (kd scientific, model 210) was used for the tandem enyne metathesis studies in table 2. A $450 \mathrm{~W} \mathrm{UV}$

\footnotetext{
${ }^{1}$ Love, J. A.; Morgan, J. P.; Trnka, T. M.; Grubbs, R. H., Angew. Chem. Int. Ed. 2002, 41, 4035-4037.
} 
immersion lamp (Ace glass catalog no. 7825-34) was used for generation of singlet oxygen.

\section{General Procedure for Cyclopentadiene Formation:}

To a $50 \mathrm{~mL}$ Schlenk flask equipped with magnetic stirbar and a rubber septum was added ruthenium carbene complex $\mathbf{1 A}\left(0.1 \mathrm{mmole}, 1.0\right.$ equiv) in $10.0 \mathrm{~mL} \mathrm{CH}_{2} \mathrm{Cl}_{2}$. Propargyl benzoate $(64.0 \mathrm{mg}, 0.4 \mathrm{mmole}, 4.0$ equiv) and this solution was stirred at ambient temperature for $1 \mathrm{~h}$. The color of the reaction mixture changed from green to deep brown after stirring for ca. $20 \mathrm{~min}$. After $1 \mathrm{~h}$, the reaction mixture was analyzed by tlc and it showed complete consumption of the ruthenium carbene complex. Concentration of the crude reaction mixture in vacuo afforded a brown oil. The latter was purified by flash column chromatography using silica gel. Elution with the indicated solvent system afforded the corresponding cyclopentadienes as pale yellow oil.

\section{Cyclopentadiene 6A}

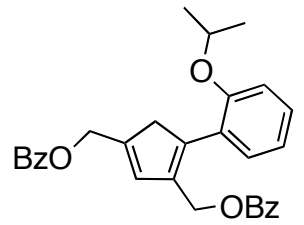

As the general experimental procedure. The cyclopentadiene 6A was obtained as a pale yellow oil (23 mg, $49 \%$ yield) upon purification of the crude reaction mixture using silica gel flash column chromatography (gradient elution with $6 \%$ ethyl acetate in hexanes followed by $10 \%$ ethyl acetate in hexanes). $\mathrm{R}_{f} 0.41(25 \%$ ethyl acetate in hexanes). ${ }^{1} \mathrm{H}-\mathrm{NMR}\left(500 \mathrm{MHz}, \mathrm{CDCl}_{3}, \mathrm{ppm}\right) \delta$ 8.09-8.07 (m, 2H), 8.04-8.02 (m, 2H), 7.57-7.53 (m, 2H), 7.45-7.41 (m, 4H), 7.24-7.21 (m, 2H), 6.96-6.92 (m, 2H), $6.73(\mathrm{~s}$, $1 \mathrm{H}), 5.22(\mathrm{~s}, 2 \mathrm{H}), 5.10(\mathrm{~s}, 2 \mathrm{H}), 4.56-4.49$ (septet, J = 6.0 Hz, 1H), $3.64(\mathrm{~s}, 2 \mathrm{H}), 1.30$ (d, J $=6.0 \mathrm{~Hz}, 6 \mathrm{H}) ;{ }^{13} \mathrm{C}-\mathrm{NMR}\left(125 \mathrm{MHz}, \mathrm{CDCl}_{3}, \mathrm{ppm}\right) \delta 166.6,166.4,155.0,142.5,141.8$, $136.1,133.0,132.9,132.5,130.9,130.2,129.7,129.64,129.63,128.6,128.35,128.31$, 126.1, 120.4, 113.9, 70.3, 63.0, 61.6, 45.9, 22.0; FT-IR (thin film, $\mathrm{cm}^{-1}$ ) 2977, 1717,

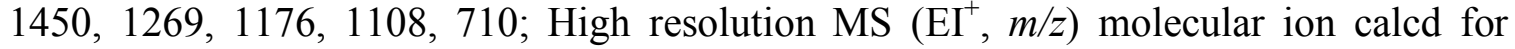
$\mathrm{C}_{30} \mathrm{H}_{28} \mathrm{O}_{5} 468.1931$, found 468.1924, error $1.7 \mathrm{ppm}$. 


\section{Nuclear Overhauser Effect Experiments on 6A}

Determination of the cyclopentadiene structure was accomplished by nOe experiments. Due to the likelihood of rapid 1,5-hydride shift, a number of tautomers could be produced in the cyclodimerization. The nOe experiments were useful in deducing the relative substitution of the alkyne substituents. The experiments below were consistent with the 1,3-disposition of alkyne substituents.

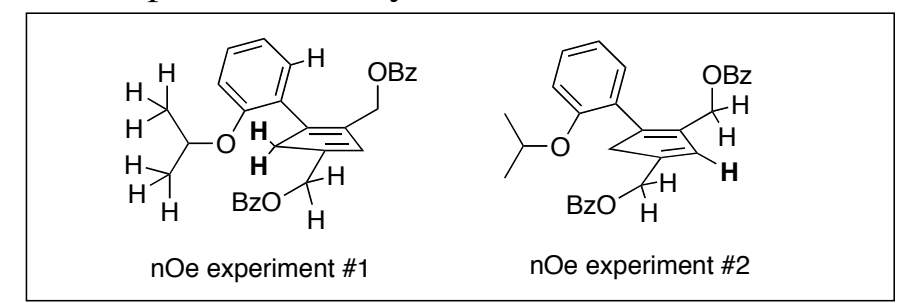

In each experiment, irradiation of the protons in bold showed enhancements to the indicated protons. In experiment \#1 (exp1), irradiation of the endocyclic methylene at $\delta$ $3.64 \mathrm{ppm}$ showed enhancements of the aromatic methine at $\delta 7.24 \mathrm{ppm}$, the downfield methylene at $\delta 5.22$ and the isopropyl methyl groups appearing at $\delta 1.30 \mathrm{ppm}$. In experiment \#2 (exp2), the endocyclic vinylic resonance at $\delta 6.8$ was irradiated, which showed enhancements of both methylene groups at $\delta 5.22$ and $\delta 5.10 \mathrm{ppm}$. These spectra are consistent with the tautomeric structure depicted as 6A rather than e.g. S1. In addition, the other possible substitution patterns on the cyclopentadiene are not consistent with the two observed nOes, in combination. The 1,2-disposition of the alkyne substituents in hypothetical structure $\mathbf{S A}$ (as a mixture of 1,5-hydride shift isomers) is possibly consistent with exp1, but not with the nOe observed in exp2. The same can be said for possible structure SD. The 1,3-disposition of alkyne substituents of structure SB is consistent with both of the observed nOes. The alternative 1,3-disposition of the alkyne substituents depicted in gross structure $\mathbf{S C}$ is not consistent with observed nOe in exp1 or $\exp 2$.
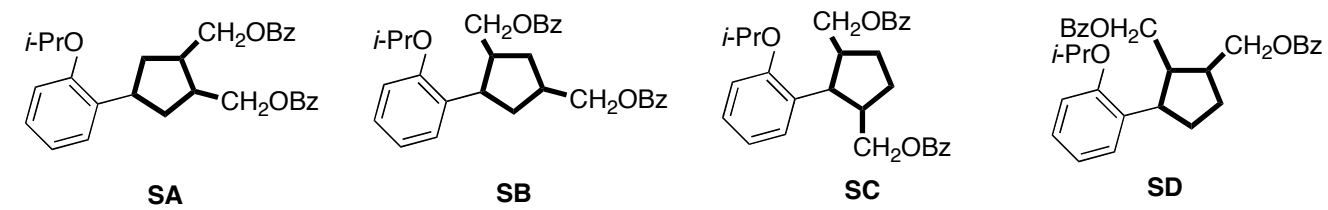


\section{Cyclopentadiene 6B}

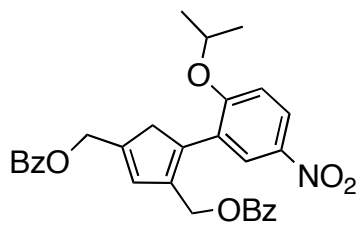

As the general experimental procedure. The cyclopentadiene $\mathbf{6 B}$ was obtained as a pale yellow oil (20 mg, $39 \%$ yield) upon purification of the crude reaction mixture using silica gel flash column chromatography (gradient elution with $8 \%$ ethyl acetate in hexanes followed by $12 \%$ ethyl acetate in hexanes). $\mathrm{R}_{f} 0.34$ (25\% ethyl acetate in hexanes). The ${ }^{1} \mathrm{H}-\mathrm{NMR}$ spectrum of $\mathbf{6 B}$, remained complex, even after flash column chromatography. The complexity is due to the presence of valence isomers produced through 1,5-hydride shift. This compound was thus not suitable for full characterization. Cyclopentadiene 6B was converted into the corresponding Diels-Alder adduct 9B, which was fully characterized as a single isomer.

\section{Diels-Alder Cycloadduct 9A}

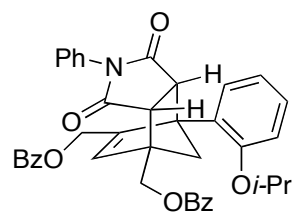

To a solution of $6 \mathrm{~A}(26.7 \mathrm{mg}, 0.057 \mathrm{mmol})$ in benzene $(1.5 \mathrm{~mL})$ was added $N$ phenylmaleimide $(19.7 \mathrm{mg}, 0.114 \mathrm{mmol})$. The resulting solution was refluxed for $12 \mathrm{~h}$. The reaction was purified by flash chromatography on silica gel (1:3 ethyl acetatehexane) and subsequently concentrated to yield $20.0 \mathrm{mg}$ of $\mathbf{9 A}$ (85\% in cycloaddition; $68 \%$ over two steps). $\mathrm{R}_{\mathrm{f}}=0.15$ (1:3 ethyl acetate-hexane). ${ }^{1} \mathrm{H} \mathrm{NMR}\left(500 \mathrm{MHz}, \mathrm{CDCl}_{3}\right)$ d $8.07(\mathrm{~m}, 2 \mathrm{H}), 7.98(\mathrm{~m}, 3 \mathrm{H}), 7.56(\mathrm{~m}, 2 \mathrm{H}), 7.42(\mathrm{~m}, 4 \mathrm{H}),(7.26(\mathrm{~m}, 4 \mathrm{H}), 7.17(\mathrm{~m}, 2 \mathrm{H})$, 7.01(t, J = 7.5 Hz, 1H), $6.87(\mathrm{~d}, \mathrm{~J}=8.0 \mathrm{~Hz}, 1 \mathrm{H}), 6.13(\mathrm{~s}, 1 \mathrm{H}), 5.13(\mathrm{dd}, \mathrm{J}=2.0,16.0 \mathrm{~Hz}$, $1 \mathrm{H}), 5.02(\mathrm{~d}, \mathrm{~J}=11.5 \mathrm{~Hz}, 1 \mathrm{H}), 4.91(\mathrm{~d}, \mathrm{~J}=12 \mathrm{~Hz}, 1 \mathrm{H}), 4.62(\mathrm{~m}, 1 \mathrm{H}), 4.30(\mathrm{~m}, 2 \mathrm{H}), 3.66$ $(\mathrm{d}, \mathrm{J}=7.5 \mathrm{~Hz}, 1 \mathrm{H}), 3.20(\mathrm{~d}, \mathrm{~J}=8.5 \mathrm{~Hz}, 1 \mathrm{H}), 1.74(\mathrm{~d}, \mathrm{~J}=9.0 \mathrm{~Hz}, 1 \mathrm{H}), 1.35$ (d, J = 6.0 Hz, $3 \mathrm{H}), 1.27(\mathrm{~d}, \mathrm{~J}=6.0 \mathrm{~Hz}, 3 \mathrm{H}) ;{ }^{13} \mathrm{C} \mathrm{NMR}\left(125 \mathrm{MHz}, \mathrm{CDCl}_{3}\right) \mathrm{d} 175.7,175.3,166.2,165.7$, 155.6, 148.3, 133.1, 133.0, 131.7, 130.6, 129.9, 129.7, 129.6, 129.1, 129.0, 128.6, 128.4, $126.7,124.7,124.4,120.0,111.4,69.1,64.1,62.6,61.9,58.4,56.8,48.7,21.8,21.7$; FTIR (thin film, $\mathrm{cm}^{-1}$ ) 3075, 2981, 1720, 1608, 1496, 1453, 1384, 1316, 1272, 1185, 1117; high resolution ESI molecular ion calcd for $\mathrm{C}_{40} \mathrm{H}_{35} \mathrm{O}_{7} \mathrm{NNa} 664.2306$, found 664.2302, error $0.6 \mathrm{ppm}$. 


\section{Diels-Alder Cycloadduct 9B}

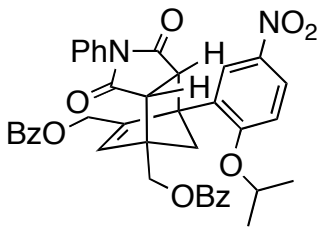

A schlenk tube ( $25 \mathrm{~mL}$ capacity) was charged with a solution of cyclopentadiene 6B $(51.3 \mathrm{mg}, 0.1 \mathrm{mmole})$ in benzene $(\mathrm{ca} .600 \mu \mathrm{L})$. Freshly recrystallized $N$-phenyl maleimide (34.6 mg, 0.2 mmole, 2.0 equiv) was added and this solution was refluxed by immersing the schlenk tube into an oil bath maintained at $80{ }^{\circ} \mathrm{C}$ for $16 \mathrm{~h}$. The reaction mixture was concentrated to afford an orange oil. This was purified by flash column chromatography using silica gel. Gradient elution with $10 \%$ ethyl acetate in hexanes (50 $\mathrm{mL})$ followed by $20 \%$ ethyl acetate in hexanes $(50 \mathrm{~mL})$ and finally with $25 \%$ ethyl acetate in hexanes afforded the desired cycloadduct 9B (49 $\mathrm{mg}, 72 \%$ yield) as a pale yellow oil. $\mathrm{R}_{f} 0.27$ (33\% ethyl acetate in hexanes). ${ }^{1} \mathrm{H}-\mathrm{NMR}\left(500 \mathrm{MHz}, \mathrm{CDCl}_{3}, \mathrm{ppm}\right) \delta$ $9.00(\mathrm{~d}, \mathrm{~J}=3.0 \mathrm{~Hz}, 1 \mathrm{H}), 8.24(\mathrm{dd}, \mathrm{J}=9.0,3.0 \mathrm{~Hz}, 1 \mathrm{H}), 8.07-8.05(\mathrm{~m}, 2 \mathrm{H}), 7.95-.93$ (m, 2H), 7.59-7.55 (m, 2H), 7.46-7.39 (m, 4H), 7.31-7.29 (m, 3H), 7.19-7.16 (m, 2H), 6.94 $(\mathrm{d}, \mathrm{J}=9.0 \mathrm{~Hz}, 1 \mathrm{H}), 6.18(\mathrm{~s}, 1 \mathrm{H}), 5.07(\mathrm{dd}, \mathrm{J}=16.0,1.5 \mathrm{~Hz}, 1 \mathrm{H}), 5.04-4.91(\mathrm{~m}, 2 \mathrm{H}), 4.76-$ 4.69 (septet, $\mathrm{J}=6.0 \mathrm{~Hz}, 1 \mathrm{H}), 4.35-4.30(\mathrm{M}, 2 \mathrm{H}), 3.72$ (d, J = 8.0 Hz, 1H), 3.12 (d, J = 9.0 $\mathrm{Hz}, 1 \mathrm{H}), 1.78(\mathrm{~d}, \mathrm{~J}=9.0 \mathrm{~Hz}, 1 \mathrm{H}), 1.40(\mathrm{~d}, \mathrm{~J}=6.0 \mathrm{~Hz}, 3 \mathrm{H}), 1.32(\mathrm{~d}, \mathrm{~J}=6 \mathrm{~Hz}, 3 \mathrm{H}) ;{ }^{13} \mathrm{C}-$ NMR (125 MHz, $\mathrm{CDCl}_{3}$, ppm) $\delta 175.2,174.9,166.1,165.7,160.9,147.1,140.9,133.2$, $131.5,129.8,129.6,129.4,129.1,129.0,128.8,128.7,128.4,126.8,126.6,126.5,126.4$, $125.9,125.5,111.3,71.6,63.8,61.9,61.4,58.2,57.0,48.9,48.4,21.6,21.4$; FT-IR (thin film, $\left.\mathrm{cm}^{-1}\right)$ 2979, 1713, 1514, 1271, 1110, 1070, 948, 712; High resolution MS (ESI ${ }^{+}$, $m / z)$ molecular ion calcd for $\mathrm{C}_{40} \mathrm{H}_{34} \mathrm{~N}_{2} \mathrm{O}_{9} \mathrm{Na}_{1}$ 709.2136, found $709.2144(\mathrm{M}+\mathrm{Na})^{+}$, error $1.7 \mathrm{ppm}$.

\section{Endoperoxide 10}

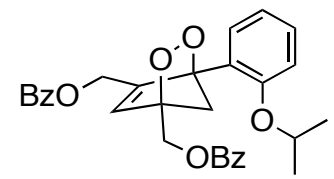

Cyclopentadiene 6A (23.4 mg, 0.05 mmole) was dissolved in $10 \mathrm{~mL} \mathrm{1,2-DCE} \mathrm{in} \mathrm{a}$ pyrex test tube $(25 \mathrm{~mL}$ capacity) equipped with a magnetic stirbar. To this solution was added a catalytic amount ( $1 \mathrm{mg}$ ) of 5,10,15,20-tetraphenyl-21H,23H-porphine (TPP). Oxygen gas was slowly bubbled through this solution. The resultant pale violet solution was then irradiated with a $450 \mathrm{~W}$ UV immersion lamp for $1 \mathrm{~h}$. Analysis of the crude reaction mixture by tlc at this stage revealed complete consumption of the cyclopentadiene 6A. The reaction mixture was concentrated in vacuo and purified by flash column chromatography using silica gel. Elution with $10 \%$ ethyl acetate in hexanes afforded the desired endoperoxide 10 (10.5 mg, $41 \%$ yield) as a pale yellow oil. $\mathrm{R}_{f} 0.29$ (25\% ethyl acetate in hexanes). ${ }^{1} \mathrm{H}-\mathrm{NMR}\left(500 \mathrm{MHz}, \mathrm{CDCl}_{3}, \mathrm{ppm}\right) \delta 8.09-8.07(\mathrm{~m}, 2 \mathrm{H})$, $7.96(\mathrm{dd}, \mathrm{J}=8.0,1.0 \mathrm{~Hz}, 2 \mathrm{H} 7), 7.59-7.53(\mathrm{~m}, 2 \mathrm{H}), 7.49-7.47(\mathrm{~m}, 1 \mathrm{H}), 7.45-7.40(\mathrm{~m}, 3 \mathrm{H})$, 7.32-7.29 (m, 1H), $6.94(\mathrm{t}, \mathrm{J}=7.5 \mathrm{~Hz}, 1 \mathrm{H}), 6.89(\mathrm{~d}, \mathrm{~J}=8.0 \mathrm{~Hz}, 1 \mathrm{H}), 6.48(\mathrm{~s}, 1 \mathrm{H}), 5.02$ $(\mathrm{dd}, \mathrm{J}=16.0,1.5 \mathrm{~Hz}, 1 \mathrm{H}), 4.94(\mathrm{dd}, \mathrm{J}=29.0,12.5 \mathrm{~Hz}, 2 \mathrm{H}), 4.71(\mathrm{dd}, \mathrm{J}=16.0,1.5 \mathrm{~Hz}$, 1H), 4.66- 4.59 (septet, $J=6.0 \mathrm{~Hz}, 1 \mathrm{H}), 3.07(\mathrm{~d}, \mathrm{~J}=9.0 \mathrm{~Hz}, 1 \mathrm{H}), 2.24(\mathrm{~d}, \mathrm{~J}=9.0 \mathrm{~Hz}, 1 \mathrm{H})$, 
$1.36(\mathrm{~d}, \mathrm{~J}=6.0 \mathrm{~Hz}, 3 \mathrm{H}), 1.32(\mathrm{~d}, \mathrm{~J}=6.0 \mathrm{~Hz}, 3 \mathrm{H}) ;{ }^{13} \mathrm{C}-\mathrm{NMR}\left(125 \mathrm{MHz}, \mathrm{CDCl}_{3}, \mathrm{ppm}\right) \delta$ 166.1, 165.9, 154.0, 148.4, 133.3, 133.0, 129.8, 129.7, 129.6, 129.4, 128.4, 128.3, 127.3, 127.2, 121.4, 120.2, 111.6, 93.2, 92.8, 69.6, 60.7, 60.6, 55.8, 21.9, 21.8; FT-IR (thin film, $\mathrm{cm}^{-1}$ ) 3387, 1721, 1597, 1451, 1273, 1143, 1026, 815, 713; High resolution MS (ESI', $m / z)$ molecular ion calcd for $\mathrm{C}_{30} \mathrm{H}_{28} \mathrm{O}_{7} \mathrm{Na}_{1} 523.1736$, found $523.1732(\mathrm{M}+\mathrm{Na})^{+}$, error 0.9 ppm.

\section{Observation of Cyclopentadienes Under Nominal Metathesis Conditions of Table 2}

with 1-Hexene

To a flame-dried, $60 \mathrm{~mL}$ test tube equipped with magnetic stirbar and a rubber septum under argon was added propargyl benzoate $(64.0 \mathrm{mg}, 0.4 \mathrm{mmole}, 4.0$ equiv) and 1-hexene (4-12 equiv) in $20.0 \mathrm{~mL}$ dichloromethane. The solution was stirred at room temperature for $5 \mathrm{~min}$, whereupon ruthenium carbene complex $\mathbf{1 A}$ ( $0.1 \mathrm{mmole}, 1.0$ equiv) was added and this solution was stirred at ambient temperature for $24 \mathrm{~h}$. The color of the reaction mixture changed from green to deep brown after stirring for ca. 2 min. After 24 $\mathrm{h}$, the reaction mixture was analyzed by tlc and showed complete consumption of the ruthenium carbene complex. Concentration of the crude reaction mixture in vacuo afforded a brown oil. Mesitylene $(4.6 \mu \mathrm{L}, 0.03$ mmole, internal standard) was added via microliter syringe along with $0.5 \mathrm{~mL}$ of deuteriochloroform and the sample was analyzed by ${ }^{1} \mathrm{H}$ NMR. The mesitylene proton appearing at $\delta 6.80 \mathrm{ppm}$ was normalized as $1.00 \mathrm{H}$. Protons $\mathrm{H}_{1}$, and $\mathrm{H}_{2}$ at $\delta 6.70$ and $3.64 \mathrm{ppm}$ were assigned to the diene 7 and cyclopentadiene $6 \mathrm{~A}$ respectively, and integrated against the internal standard to obtain the values summarized in Table S1. (Note: integration for $\mathrm{H}_{2}$ is divided by 2 to obtain the percent of 6A).

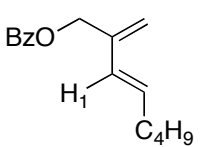

7

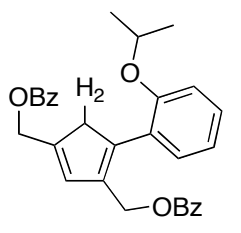

6A

The results of these runs are summarized in Table S1. In entries that contain two numbers, these are the results of each run performed in duplicate. Entries 1-3 and entries 4-6 were obtained with different samples of carbene complex 1A. Under these conditions, the alkyne was completely consumed and the carbene complex $\mathbf{1 A}$ was completely consumed. The yields were determined by integration vs. internal standard. 
Table S1. Byproduct 6A and 1,3-Diene Under Enyne Metathesis Conditions

\begin{tabular}{|l|l|l|l|}
\hline Entry & {$[1$-hexene $]$} & Cyclopentadiene 6A & Diene 7 \\
\hline 1 & $20 \mathrm{mM}$ & 8,12 & $33,24(\mathrm{av}=29)$ \\
\hline 2 & $40 \mathrm{mM}$ & 4,4 & $37,44(\mathrm{av}=40)$ \\
\hline 3 & $60 \mathrm{mM}$ & Not observed & $50,51(\mathrm{av}=51)$ \\
\hline $4^{*}$ & $20 \mathrm{mM}$ & 10 & 30 \\
\hline $5^{*}$ & $40 \mathrm{mM}$ & 5 & 39 \\
\hline $6^{*}$ & $60 \mathrm{mM}$ & Not observed & 44 \\
\hline \multicolumn{2}{|l|}{${ }^{*}$ A different sample of carbene complex was used in these runs } \\
\hline
\end{tabular}

with 1,5-Cyclooctadiene

To a flame-dried, $60 \mathrm{~mL}$ test tube equipped with magnetic stirbar and a rubber septum under argon was added propargyl benzoate $(64.0 \mathrm{mg}, 0.4 \mathrm{mmole}, 4.0$ equiv) and 1,5-cyclooctadiene (4-12 equiv) in $20.0 \mathrm{~mL}$ dichloromethane. The solution was stirred at room temperature for $5 \mathrm{~min}$, whereupon ruthenium carbene complex $\mathbf{1 A}(0.1 \mathrm{mmole}, 1.0$ equiv) was added and this solution was stirred at ambient temperature for $24 \mathrm{~h}$. The color of the reaction mixture changed from green to deep brown after stirring for ca. $2 \mathrm{~min}$. After $24 \mathrm{~h}$, the reaction mixture was analyzed by tlc and showed complete consumption of the ruthenium carbene complex. Concentration of the crude reaction mixture in vacuo afforded a brown oil. Mesitylene $(4.6 \mu \mathrm{L}, 0.03 \mathrm{mmole}$, internal standard) was added via microliter syringe along with $0.5 \mathrm{~mL}$ of deuteriochloroform and the sample was analyzed by ${ }^{1} \mathrm{H}$ NMR. The mesitylene proton appearing at $\delta 6.80 \mathrm{ppm}$ was normalized as $1.00 \mathrm{H}$. Protons $\mathrm{H}_{\mathrm{A}}$, and $\mathrm{H}_{\mathrm{B}}$ at $\delta 4.78$ and 3.64 ppm were assigned to the cyclohexadiene 8 and cyclopentadiene $6 \mathrm{~A}$ respectively, and integrated against the internal standard to obtain the values summarized in Table S2.

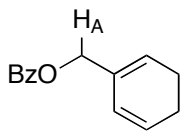

8

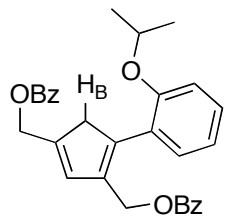

$6 \mathrm{~A}$

The results of these runs are summarized in Table S2. Under these conditions, the alkyne was completely consumed and the carbene complex $\mathbf{1 A}$ was completely consumed. The yields were determined by integration vs. internal standard.

Table S2. Byproduct and 1,3-Cyclohexadiene Under Methylene-Free Conditions

\begin{tabular}{|l|l|l|l|}
\hline Entry & {$[1,5-\mathrm{COD}]$} & Cyclopentadiene 6A & Cyclohexadiene 8 \\
\hline 1 & $20 \mathrm{mM}$ & 20 & $30(20)^{\mathrm{a}}$ \\
\hline 2 & $40 \mathrm{mM}$ & 12 & 40 \\
\hline 3 & $60 \mathrm{mM}$ & 8 & $55(48)^{\mathrm{a}}$ \\
\hline (a) Isolated yield &
\end{tabular}




\section{NMR Spectra}

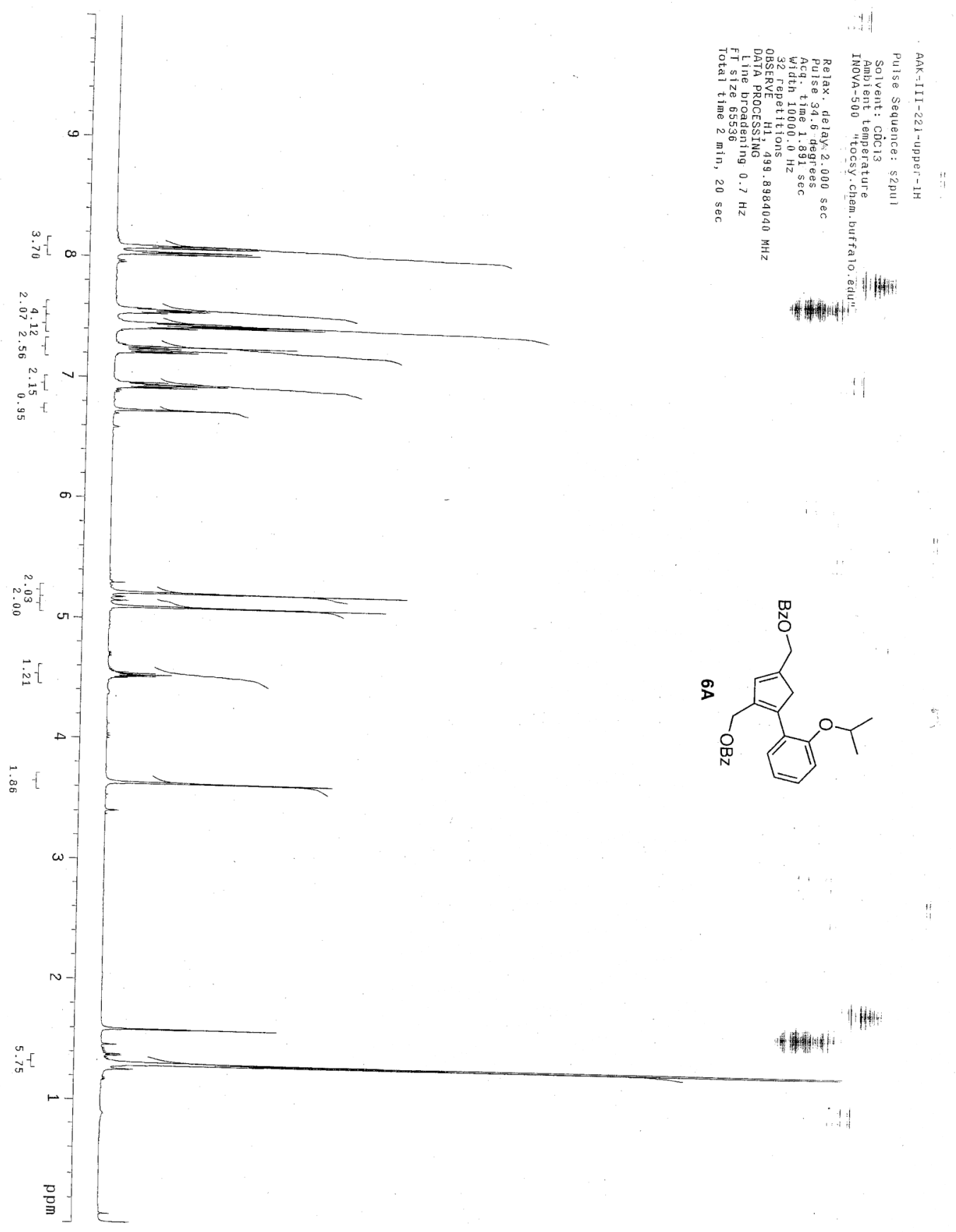




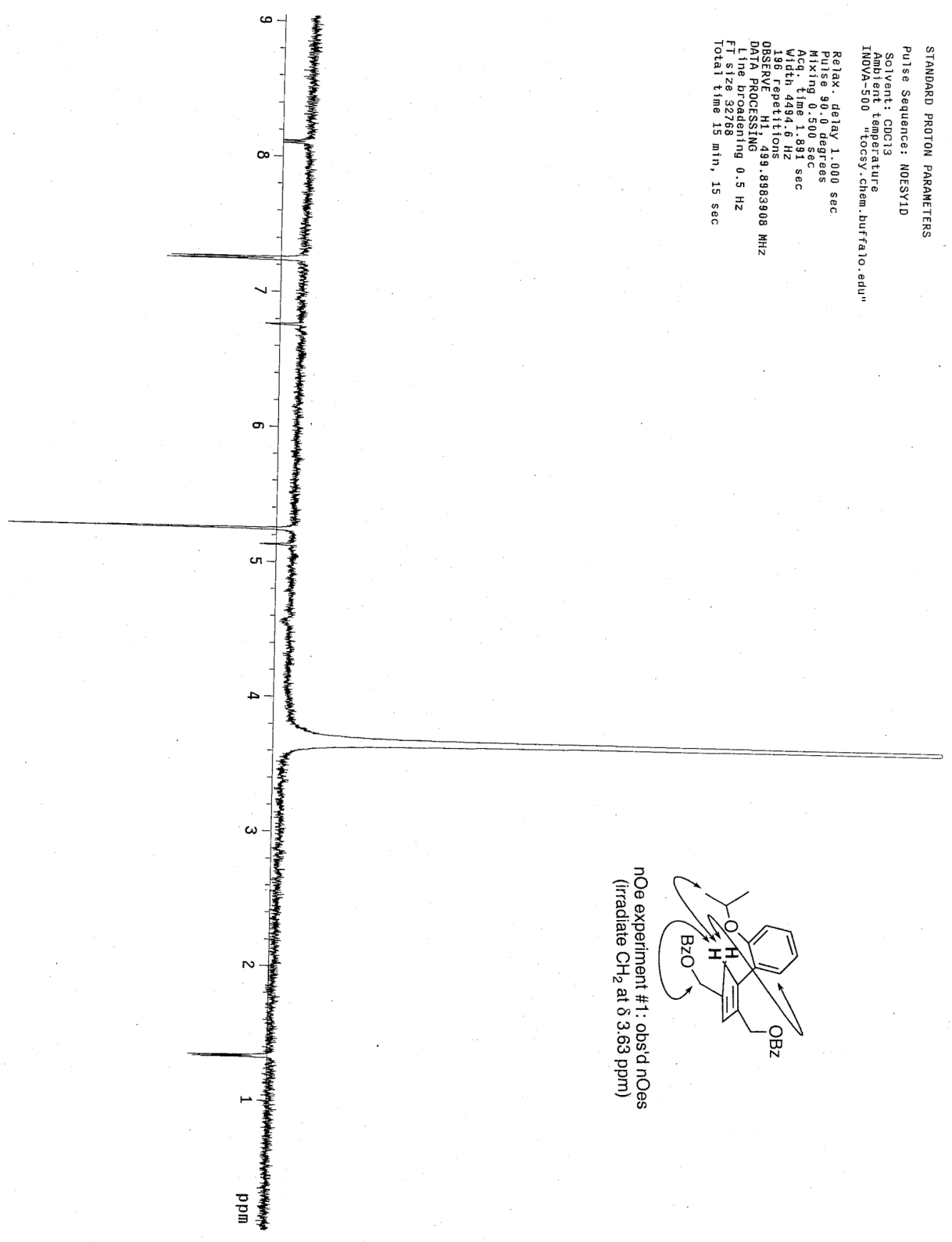




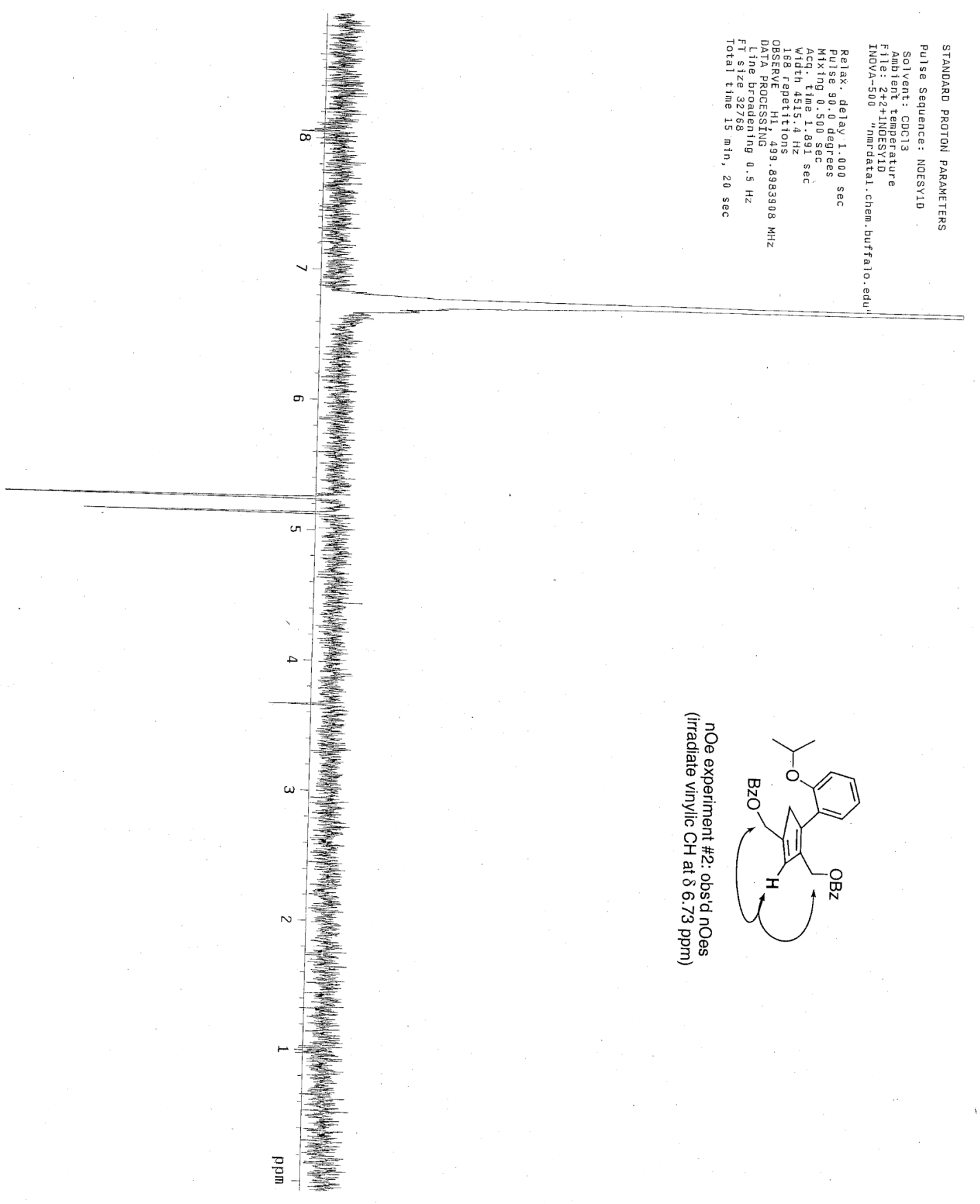




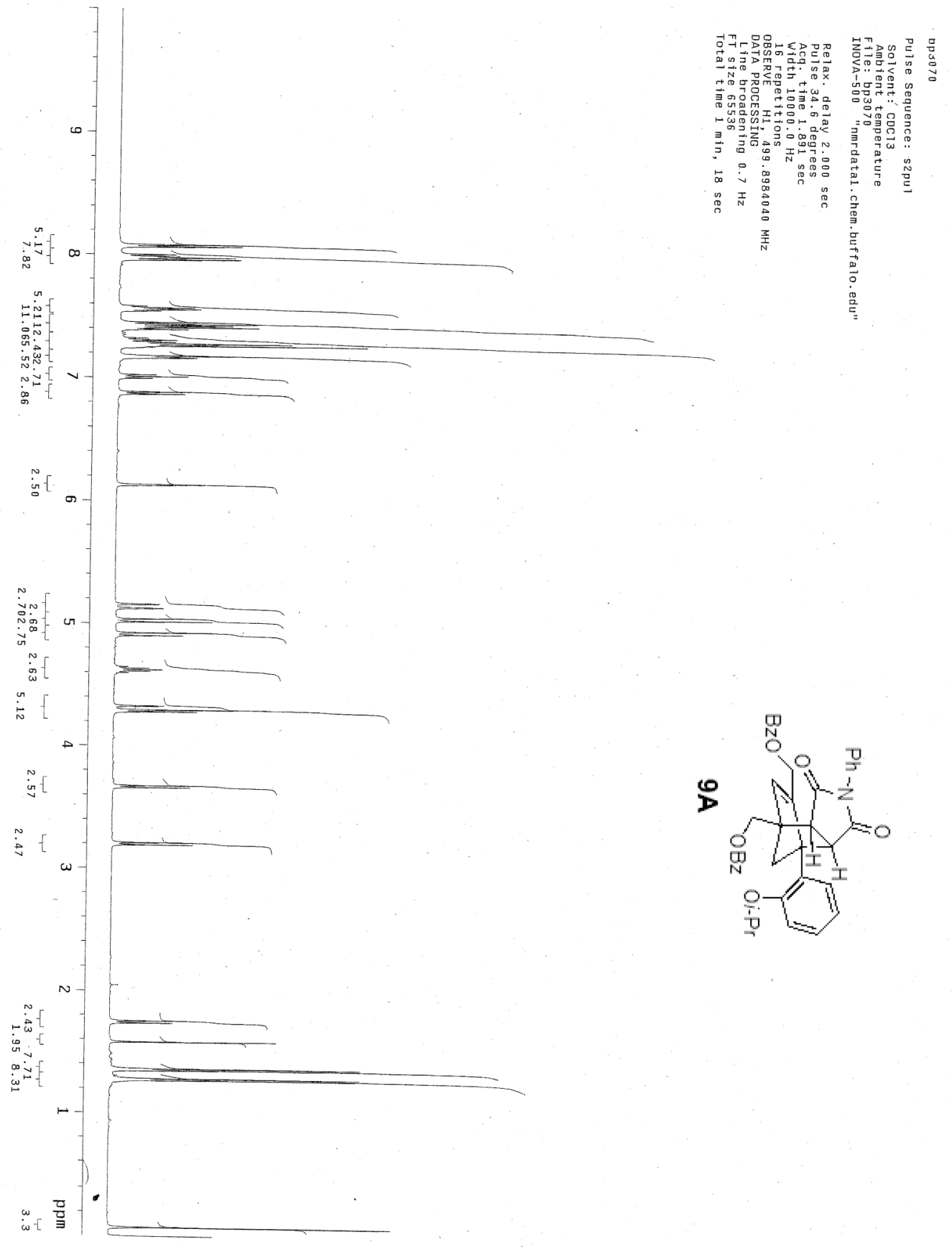




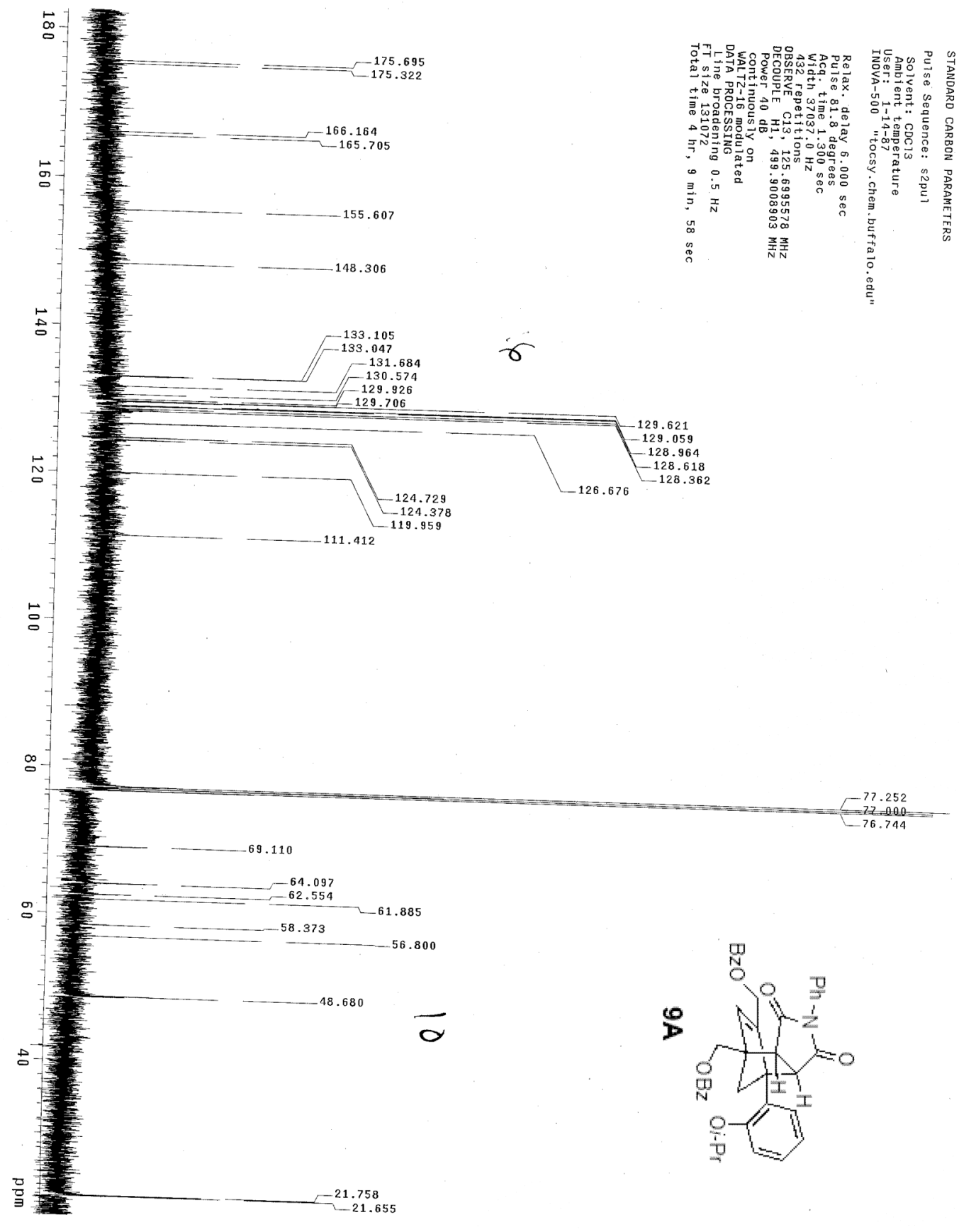




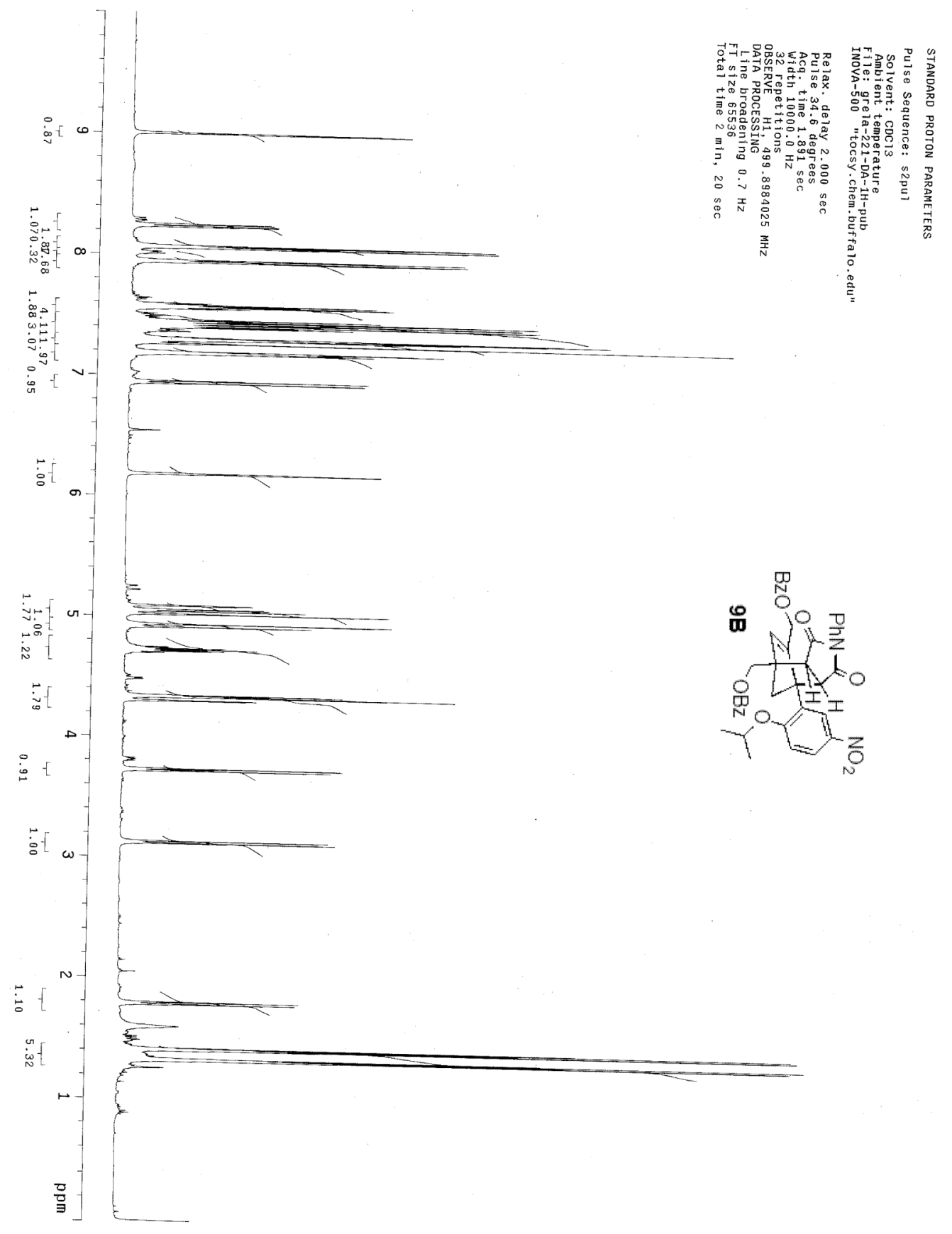




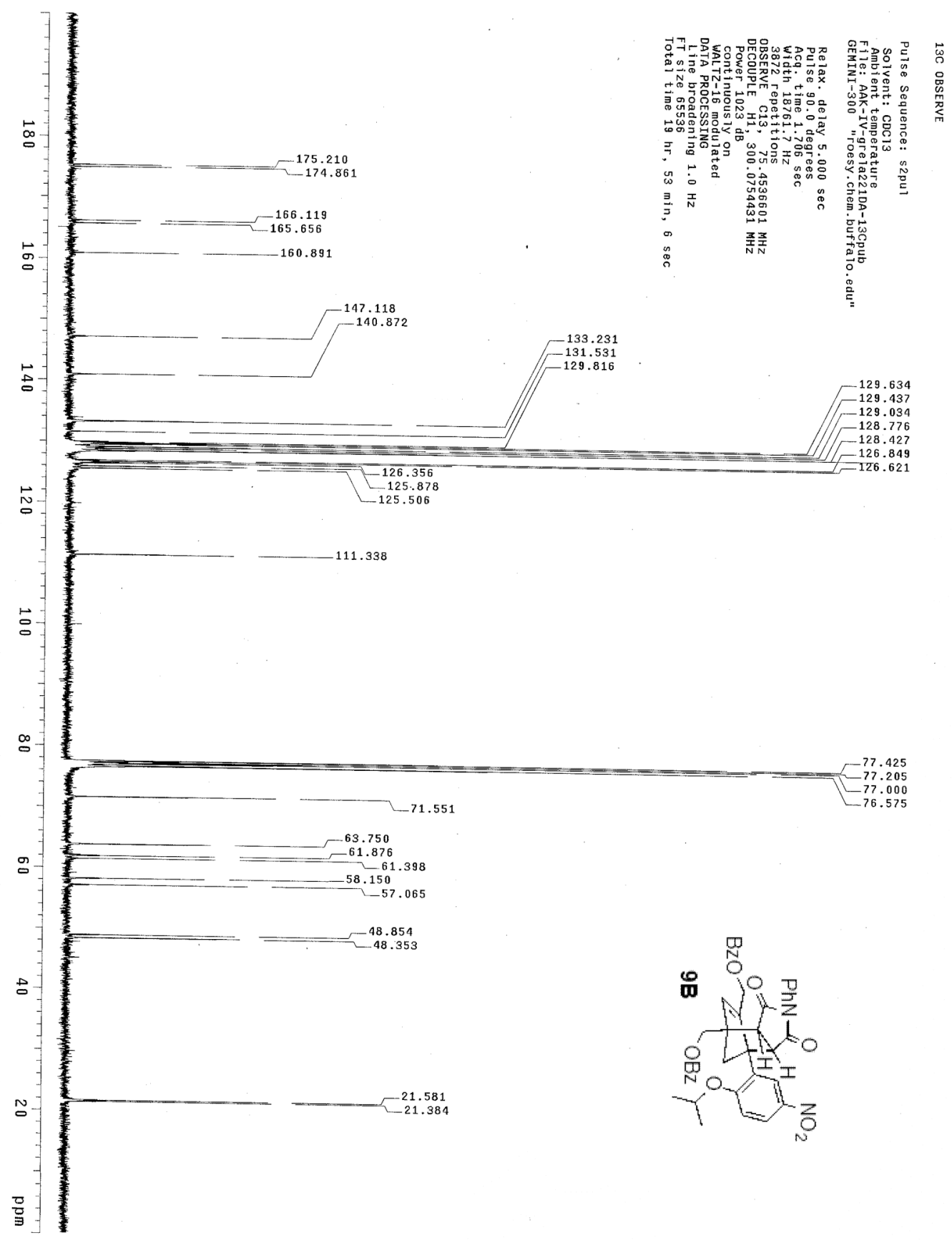




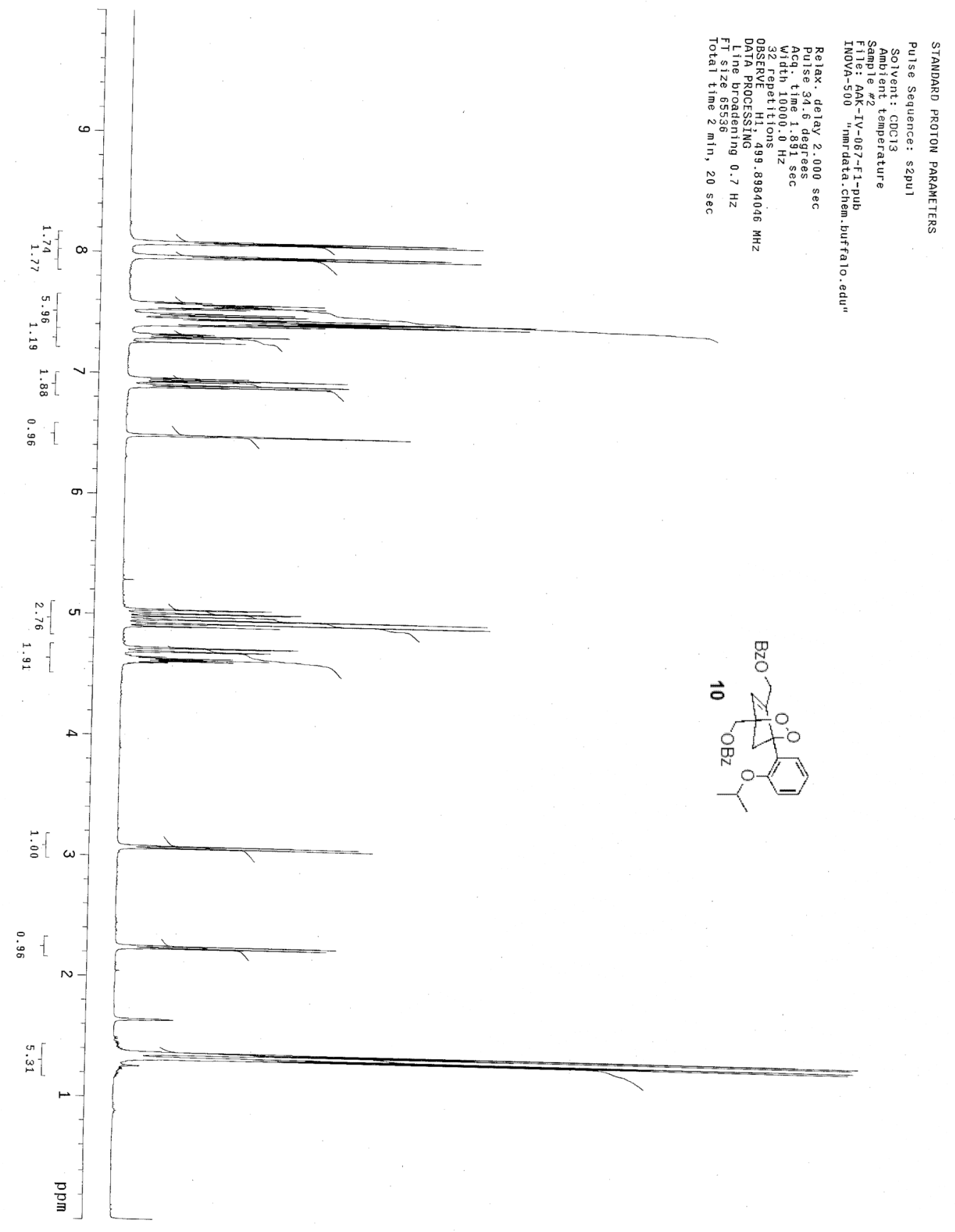




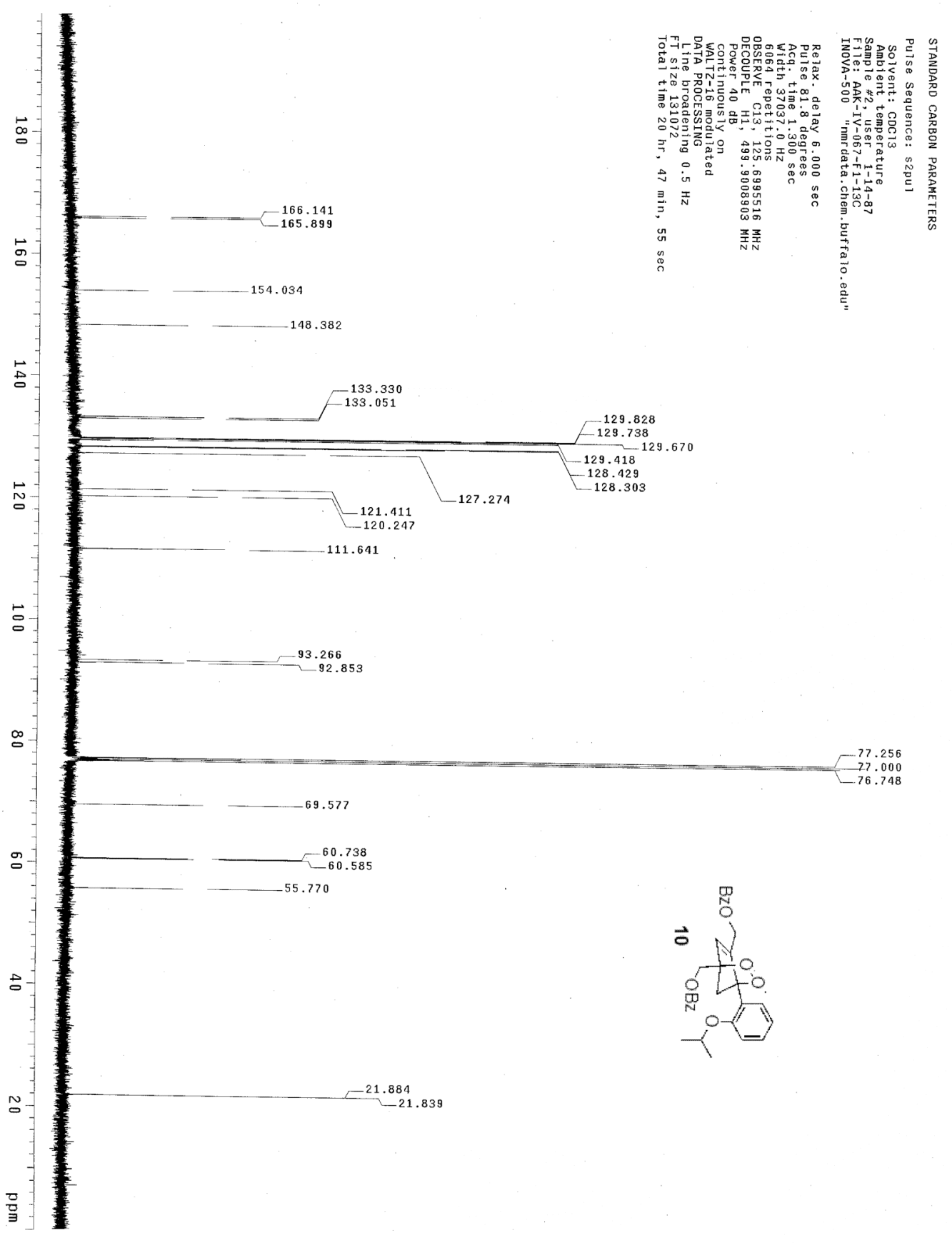

